\title{
IMPACT OF TENT CATERPILLAR DEFOLIATION ON THE REPRODUCTIVE SUCCESS OF BLACK-CAPPED CHICKADEES ${ }^{1}$
}

\author{
Shawna Pelech and Susan J. Hannon \\ Department of Biological Sciences, University of Alberta, Edmonton, Alberta T6G $2 E 9$ Canada
}

Key words: Chickadee; Parus atricapillus; tent caterpillar; Malacosoma disstria; breeding biology; defoliation.

Outbreaks of folivorous Lepidoptera caterpillars are common in temperate forests (Ives and Wong 1988, Butterworth 1990). The high fat content, low chitin content, and large size of these larvae make them an important component of the diet of many temperate birds (Betts 1955, Robinson and Holmes 1982, Holmes and Schultz 1988, Sample et. al. 1993). Outbreaks of most species should increase available food for breeding birds, improving their reproductive success. Some caterpillars, however, have morphological or chemical defenses that make them unpalatable to avian predators (Heinrich and Collins 1983). During outbreaks, these species have the potential to reduce the abundance of palatable caterpillars through severe defoliation. Previous studies have not considered the effects of outbreaks of unpalatable Lepidoptera species on the breeding biology of birds.

This investigation determines the effects of forest tent caterpillar (Malacosoma disstria) outbreaks on the reproductive success of Black-capped Chickadees (Parus atricapillus) near Athabasca, Alberta, Canada. The tent caterpillar is a major defoliator of trembling aspen (Populus tremuloides) in Alberta, undergoing three to five year population outbreaks every five to ten years (Ives and Wong 1988, Butterworth 1990). Egg masses and very early instar larvae can be consumed by avian predators. Thus, for resident bird species, an outbreak of tent caterpillars could increase food supply in winter and early spring prior to and just after hatch of egg masses. Late instar tent caterpillars, however, are equipped with spiny hairs and bristles and are unpalatable to most avian predators (Smith 1991). Thus, outbreaks of tent caterpillars that lead to defoliation during the brood-rearing period may decrease reproductive success for chickadees.

Tent caterpillar outbreaks and complete canopy tree defoliation occurred in our study area during 1986 and 1987 , while few or no caterpillars and little or no defoliation were evident during 1989-1992. We tested two predictions. First, in years with tent caterpillar outbreaks, initiation of breeding would be earlier and clutch sizes larger in response to extra food when compared to years with no outbreaks. Second, tent caterpillar defoliation would reduce the reproductive suc-

${ }^{1}$ Received 1 February 1995. Accepted 4 May 1995. cess and subsequent survival of female Black-capped Chickadees through food limitation during brood-rearing.

\section{STUDY AREA AND METHODS}

Study area. This study was conducted at the Meanook Biological Research Station near Athabasca, Alberta $\left(54^{\circ} 37^{\prime} \mathrm{N}, 113^{\circ} 20^{\prime} \mathrm{W}\right)$ from early April to early July in 1986,1987 , and $1989-1992$. The $2 \mathrm{~km}^{2}$ study area at Meanook consisted of trembling aspen and Balsam poplar $(P$. balsamifera) stands intermixed with willow (Salix spp.) and open fields (also see Desrochers et al. 1988). In 1986 and 1987, data from chickadee nests in adjacent areas were collected and included in our analysis. Although there were over a hundred nest boxes at Meanook and surrounding areas, few were used by chickadees.

Capture and banding. Most adult chickadees were captured between December and March of each year by attracting birds to mist nets using feeders filled with sunflower seeds. During the breeding season, any unbanded adults were netted at nest cavity holes. Birds were given a numbered metal band, and three plastic colored bands covered with electrician's tape of the same color to form $0.5 \mathrm{~cm}$ long flags to aid in identification. Sex was determined by observing breeding and nesting behavior or using a discriminant analysis of body size measures (Desrochers 1990).

Measures of reproductive success and survival. Starting in early April each year, the study area was searched for chickadee pairs excavating nest cavities or preparing nest boxes. Once a nest was found, we observed the pair for forty-five minutes to one hour at least twice to confirm nesting or to determine if the cavity had been abandoned. Incubation was considered to have started when the female spent long periods on the nest and only left briefly to forage for short periods. Once incubation started we observed nests every three to four days to determine the date of hatching and fledging. For cavities that we could not see into, we knew hatching had occurred when the male entered the cavity with food when the female was absent, and observations of family groups outside the nest confirmed fledging of chicks.

Nests in boxes or accessible cavities were checked for clutch size, nestling number, dead nestlings or unhatched eggs. Chicks in these nests were banded 2-4 days before the estimated date of fledge, with nestling period assumed to be 16 days (Smith, 1991). Chicks were given a numbered metal band and one colored leg band. Nestlings were weighed to the nearest $0.5 \mathrm{~g}$ with a $50 \mathrm{~g}$ Pesola spring scale. Flattened wing length was measured to the nearest $\mathrm{mm}$. 
TABLE 1. Comparison of date of clutch initiation (Julian date), clutch size, nestling period length, mass of chicks, and number of chicks fledged of Black-capped Chickadees between years with and without tent caterpillar defoliation, $\overline{\mathrm{x}} \pm \mathrm{SE}(n) .^{1}$

\begin{tabular}{lccccc}
\hline \hline Year & $\begin{array}{c}\text { Date of clutch } \\
\text { initiation }\end{array}$ & Clutch size & $\begin{array}{c}\text { Nestling } \\
\text { period length } \\
\text { (days) }\end{array}$ & $\begin{array}{c}\text { Mass of chicks } \\
(\mathrm{g})^{2}\end{array}$ & $\begin{array}{c}\text { Number } \\
\text { fledged }\end{array}$ \\
\hline $\begin{array}{c}\text { Defoliated } \\
(1986-1987)\end{array}$ & $135.2 \pm 2.2$ & $6.5 \pm 0.4$ & $14.4 \pm 1.9$ & $10.1 \pm 0.3$ & $5.9 \pm 0.8$ \\
Non-defoliated & $(20)$ & $(47)$ & $(9)$ & $(17)$ & $(40)$ \\
$\quad(1989-1992)$ & $(24)$ & $7.3 \pm 0.5$ & $16.5 \pm 0.9$ & $10.5 \pm 0.2$ & $5.8 \pm 1.0$ \\
Significance & $F=0.47, P=$ & $F=0.97, P=$ & $F=0.72, P=$ & $F=0.68, P=$ & $F=0.01, P=$ \\
Level & $0.50, \mathrm{df}=41$ & $0.33, \mathrm{df}=74$ & $0.40, \mathrm{df}=30$ & $0.42, \mathrm{df}=30$ & $0.92, \mathrm{df}=67$ \\
\hline
\end{tabular}

All means were adjusted for year covariate.

${ }^{2}$ Mean masses were adjusted for age at weighing, wing length, and clutch size covariates.

Date of clutch initiation was estimated by back-dating, assuming females laid one egg per day and had a 12 day incubation period from the day of the penultimate egg (Smith, 1991). For nests where clutch size was not known, we used the modal clutch size of seven, or the brood size (if accurate) as an estimate. In most cases, dates of clutch initiation, hatch, and fledge had to be estimated as we did not visit the nests daily. For example, if a nest had not hatched on June 5 and was hatched on June 9 , the estimated hatch date was June 7 with a confidence limit, corresponding to the number of days between visits, of three. Only estimates for which the confidence limit was less than five days were used in the analysis.

Nestling period length was calculated by subtracting date of hatch from date of fledge. Fledging success was defined as the proportion of chicks fledging of those that hatched. When determining the frequency of nest abandonment and nests with dead nestlings, nests with obvious signs of predation (e.g., disturbance of cavity entrance) were not included, as we wished to include only factors expected to be directly influenced by defoliation (i.e., starvation). The adult survival rate was defined as the proportion of females breeding in one year that returned the following year.

We obtained weather records for the Athabasca weather station located $20 \mathrm{~km}$ to the north of Meanook. We used data from 1 April through 14 May, the spring period prior to clutch initiation for most years (see Table 1). The following variables were used: mean spring temperature, number of days with precipitation, number of days with snow, and number of days with a mean temperature $5^{\circ} \mathrm{C}$ below the average spring temperature for $1986,1987,1989-1992$ combined.

Due to low sample sizes, we combined years of heavy defoliation and years of little or no defoliation after determining that there were no statistically significant differences in breeding and survival variables within grouped years. Analysis of covariance (ANCOVA) was used to compare most breeding variables between outbreak and non-outbreak years using year as a covariate to further account for any year effects. Age at weighing, wing length, and clutch size were also used as covariates in the comparison of the mass of chicks between combined years. Fledging success was not normally distributed, therefore Mann Whitney $U$-tests were used to test for differences between years with or without tent caterpillar outbreaks. Goodness of fit $G$-tests were used to examine differences in the frequency of abandonment, partial nest loss, and female survival rates.

\section{RESULTS}

Outbreaks of tent caterpillars appeared to have no effect on the timing of clutch initiation or clutch size (Table 1). Since clutch initiation could have been influenced by spring weather, we correlated mean spring temperature, number of days with precipitation, number of days with snow, and number of days with a mean temperature $5^{\circ} \mathrm{C}$ below the average temperature for each year with mean date of clutch initiation for each year using a Spearman rank correlation. While none of these measures of spring weather were significantly correlated with date of clutch initiation (Spear$\operatorname{man} r=0.43,-0.20,-0.41,-0.38$ respectively, all

TABLE 2. Comparison of fledging success, partial or total brood loss, nest abandonment, and female overwinter survival in Black-capped Chickadees between years with and without tent caterpillar defoliation, $\overline{\mathbf{x}} \pm \mathrm{SE}(n)$.

\begin{tabular}{|c|c|c|c|c|}
\hline Year & Fledging success & $\begin{array}{l}\text { \% of nests with } \\
\text { partial or total } \\
\text { brood loss }\end{array}$ & $\begin{array}{l}\% \text { of nests } \\
\text { abandoned }\end{array}$ & $\begin{array}{l}\% \text { of females } \\
\text { surviving winter }\end{array}$ \\
\hline $\begin{array}{l}\text { Defoliated } \\
\quad(1986-1987)\end{array}$ & $\begin{array}{c}0.88 \pm 4.3 \\
(39)\end{array}$ & $\begin{array}{l}11.8 \\
(76)\end{array}$ & $\begin{array}{c}5.3 \\
(76)\end{array}$ & $\begin{array}{c}56.4^{1} \\
(55)\end{array}$ \\
\hline $\begin{array}{c}\text { Non-defoliated } \\
(1989-1992)\end{array}$ & $\begin{array}{c}0.94 \pm 4.9 \\
(30)\end{array}$ & $\begin{array}{r}2.3 \\
(86)\end{array}$ & $\begin{array}{l}1.2 \\
(86)\end{array}$ & $\begin{array}{l}57.8 \\
(64)\end{array}$ \\
\hline Significance Level & $U=525, P=0.26$ & $\begin{array}{c}G=5.85, P= \\
0.01, \mathrm{df}=1\end{array}$ & $\begin{array}{c}G=2.38, P= \\
0.14, \mathrm{df}=1\end{array}$ & $\begin{array}{c}G=0.02, P= \\
0.87, \mathrm{df}=1\end{array}$ \\
\hline
\end{tabular}

' Only survival rates of females breeding in 1986 were used as no sighting or breeding records for 1988 were available to determine survival of females breeding in 1987 . 
$P>0.05, n=6$ ), the low sample size and weakness of the test suggest careful interpretation of these results.

The length of the nestling period and the number of chicks fledged between years with and without defoliation were not significantly different (Table 1). The mass of chicks also did not show significant differences between defoliated and non-defoliated years (Table 1). While fledging success did not differ between defoliated and non-defoliated years, the number of nests that experienced partial or total nestling failure was significantly greater in the defoliated years (Table 2). Complete nest abandonment (after hatch) also was more frequent in outbreak years than in years without tent caterpillar defoliation, though not significantly so. Female survival to the next breeding season did not appear to be affected by tent caterpillar defoliation (Table 2).

\section{DISCUSSION}

Our first prediction was that chickadees should lay earlier and increase clutch size during tent caterpillar outbreaks, similar to other species of passerines during natural or experimental increases in food (e.g., von Bromssen and Jansson 1980, Arcese and Smith 1988, Clamens and Isenmann 1989, Nilsson 1991, Nilsson and Svenson 1993). This prediction was not supported. We observed chickadees foraging on tent caterpillar egg masses and early instar larvae, but more detailed study on the relative importance and nutritive value of this food source is needed to further test this prediction.

Our second prediction was that during heavy defoliation during brood-rearing, chickadees should have decreased reproductive success and survival. This prediction was partly supported, since during defoliated years a greater frequency of nest abandonment and partial loss of broods occurred. However, nestling period length, mass of nestlings, number of chicks fledged, fledging success, and probability of female survival to the next breeding season were similar between defoliated and non-defoliated years. These results suggest that most pairs experienced little difficulty in raising young, while others had to abandon their nests or had partial loss of the brood by starvation.

The severe defoliation in 1986 and 1987 may have reduced the abundance of palatable Lepidopteran larvae which require aspen foliage for food or as a surface for oviposition, such as the large aspen tortrix (Choristoneura conflictana) and the bruce spanworm (Operophtera bruceta) (Ives and Wong 1988, Butterworth 1990). Outbreaks of the large aspen tortrix appear to peak two to three years prior to tent caterpillar outbreaks and decline during the first years of tent caterpillar peak densities (Ives and Wong 1988), suggesting a possible negative interaction. If alternative prey, not affected by defoliation, were available in the habitat, then chickadees may have switched to these prey during years of heavy defoliation. Some songbirds increase the proportions of non-Lepidopteran insects in their breeding diet when caterpillar populations are experimentally reduced (Rodenhouse and Holmes 1992). If understory vegetation experienced increased growth as a result of a decrease in canopy cover, any consequent increase in insect abundance in the under- story may have been an alternative food source. Chickadees are quite plastic in their choice of foraging location on different tree species in relation to prey abundance (Sturman 1968, Heinrich and Collins 1983, Holmes and Schultz 1988).

Even though tent caterpillars may have reduced the number of palatable larvae during outbreak years, the amount of food may still have been above the threshold necessary for successful breeding. For example, experimental reductions in Lepidoptera caterpillars during the breeding season had few reproductive consequences for three other passerines (Powell 1984, Rodenhouse and Holmes 1992, Adams et al. 1994). Sample et al. (1993) and Whitemore et al. (1993) found that resident Black-capped Chickadees and Tufted Titmice ( $P$. bicolor), in comparison to seven migrant songbird species, were least affected by reductions in caterpillar abundance in terms of diet shifts and fat loss.

Thus, we conclude that tent caterpillar outbreaks did not influence the earliest breeding parameters (date of clutch initiation, clutch size) and may not have represented a significant increase to the food supply of chickadees. During the brood-rearing period, when defoliation was at its peak, some pairs had reduced reproductive success in the form of complete or partial loss of the brood to starvation. Future work on the impacts of defoliating insects which are unpalatable to birds should concentrate on measuring changes in the diet of birds, determining availability of preferred prey, and measuring the variation in impacts on territories within the population during outbreaks.

We thank P. Chauvet, A. Desrochers, K. Lange, C. McCallum, K. Nordin, S. Radke-Kallal, N. Rekman, R. Shortt, N. Sodhi, and J. Waterman for field assistance, C. McCallum for data management, and the staff at the Meanook Biological Station for logistical help. T. Thompson, Dept. Geography, University of Alberta supplied weather records. Funding was provided by the Canadian Circumpolar Institute (BAR grant) and Natural Sciences and Engineering Research Council grants to SJH. J. Roland and two anonymous reviewers provided helpful comments on the MS.

\section{LITERATURE CITED}

Adams, J. S., R. L. KNight, L. C. McEwen, And T. L. George. 1994. Survival and growth of nestling vesper sparrows exposed to experimental food reductions. Condor 96:739-748.

ARCESE, P., AND J.N.M. SMITH. 1988. Effects of population density and food on reproduction in song sparrows. J. Anim. Ecol. 57:119-136.

BetTs, M. M. 1955 . The food of titmice in oak woodland. J. Anim. Ecol. 24:282-323.

BUTTERWORTH, E. 1990. Review of the impact of hardwood defoliators on aspen and poplar. Part I. Review of existing information. Butterworth Consulting Ltd., Edmonton, Alberta.

Clamens, A., AND P. Isenmann. 1989. Effect of supplemental food on the breeding of Blue and Great Tits in Mediterranean habitats. Ornis Scand. 20: 36-42.

Desrochers, A. 1990. Sex determination of Blackcapped Chickadees with a discriminant analysis. J. Field. Ornith. 61:79-84. 
Desrochers, A., S. J. Hannon, and K. E. Nordin. 1988. Winter survival and territory acquisition in a northern population of Black-capped Chickadees. Auk 105:727-736.

Heinrich, B., AND S. L. Collins. 1983. Caterpillar leaf damage, and the game of hide-and-seek with birds. Ecology 64:592-602.

Holmes, R. T., AND J. C. Schultz. 1988. Food availability for forest birds: effects of prey distribution and abundance on bird foraging. Can. J. Zool. 66: $720-728$.

Ives, W.G.H., AND H. R. WONG. 1988. Tree and shrub insects of the prairie provinces. Can. For. Serv., North. For. Cent., Edmonton, Alberta. Inf. Rep. NOR-X-292.

Nilsson, J. 1991. Clutch size determination in the Marsh Tit (Parus palustris). Ecology 72:1757-1762.

Nilsson, J., And E. Svensson. 1993. Energy constraints and ultimate decisions during egg-laying in the Blue Tit. Ecology 74:244-251.

Powell, G.V.N. 1984. Reproduction by an altricial songbird, the Red-winged Blackbird, in fields treated with the organophosphate insecticide Fenthion. J. Appl. Ecol. 21:83-95.

Robinson, S. K., AND R. T. Holmes. 1982. Foraging behavior of forest birds: the relationships among search tactics, diet, and habitat at structure. Ecology 63(6): 1918-1931.

RoDENHouse, N. L., AND R. T. Holmes. 1992. Results of experimental and natural food reductions for breeding Black-throated Blue Warblers. Ecology $73(1): 357-372$.

Sample, B. E., R. J. Cooper, and R. C. Whitmore. 1993. Dietary shifts among songbirds from a diflubenzuron-treated forest. Condor 95:616-624.

SMITH, S. 1991. The black-capped chickadee: behavioural ecology and natural history. Comstock Publishing Associates, Ithaca, NY.

Sturman, W. A. 1968. The foraging ecology of Parus atricapillus and $P$. rufescens in the breeding season, with comparisons with other species of Parus. Condor 70:309-322.

von Bromssen, A., AND C. Jansson. 1980. Effects of food addition to Willow Tit Parus montanus and Crested Tit $P$. cristatus at the time of breeding. Ornis Scand. 11:173-178.

Whitmore, R. C., R. J. Cooper, and B. E. Sample. 1993. Bird fat reductions in forests treated with Dimilin. Environ. Toxicol. Chem. 12:2059-2064.

\title{
VICINITY OF SPARROWHAWK NEST AFFECTS WILLOW TIT NEST DEFENSE ${ }^{1}$
}

\author{
Seppo Rytkönen and Mikael Soppela \\ Department of Zoology, University of Oulu, P.O.B. 333, FIN-9057I Oulu, Finland
}

Key words: Willow Tit; Parus montanus; Sparrowhawk; Accipiter nisus; predation; nest defense; parental investment; experience.

Offspring defense from predators is an important component of parental investment (Trivers 1972). Predation is a strong selective pressure and organisms with parental care often enhance the survival chances of their offspring by defending these from potential predators (e.g., Gottfried 1979, Brunton 1990). Offspring defense of breeding animals includes alarm calling, distraction displays, threat or attack responses (e.g., Bjerke et al. 1985, Montgomerie and Weatherhead 1988). Beside the increased benefits (Anderson et al. 1980, GreigSmith 1980, Blancher and Robertson 1982, Brunton 1990), defense behavior also has its costs due to injuries or death (Curio and Regelmann 1985, 1986; Montgomerie and Weatherhead 1988; Brunton 1990). The costs of defense are therefore strongly affected by the danger of the predator towards which the responses are directed. When optimizing nest defense behavior, the defender should take into account the capabilities of

\footnotetext{
${ }^{1}$ Received 23 March 1995. Accepted 12 June 1995.
}

the predator (e.g., Brunton 1990) and then adjust the level of defense according to the expected benefits and costs (Montgomerie and Weatherhead 1988). Animals may have innate information of the potential danger of different predators, and they can learn this from experience (Curio 1978, Curio and Regelmann 1985).

Experience with predators can theoretically have various effects on parental nest defense behavior. Parental investment theory predicts at least four different patterns. (I) If parents learned about the capabilities of the predator during frequent encounters, experienced parents would be able to undergo higher defense intensity than inexperienced birds with the same risklevel (Montgomerie and Weatherhead 1988). (II) If frequent encounters did not lead to a real threat for the parent or the offspring of being preyed upon, parents might learn that the risk, and consequently, the costs of defense are decreased. This would then favor increased nest defense intensity with experience (Coleman 1987, Montgomerie and Weatherhead 1988). Alternatively, Knight and Temple (1986) argued that "positive reinforcement" and "loss of fear" could explain increased defense intensity with experience without any cost/benefit analyses (but see Coleman 1987, Rytkönen et al. 1990). Alternatively, frequent encounters with a predator may also increase risk for the parent or the offspring, since predators can increase their 